\title{
Development, Reliability, and Validity of the Home Blood Pressure Monitoring Adherence Scale for Patients with Chronic Kidney Disease
}

This article was published in the following Dove Press journal: Patient Preference and Adherence

\author{
Yamin Wang $\mathbb{D}^{1, *}$ \\ Kun $\mathrm{Li}^{1}{ }^{1} *$ \\ Huiqun $\mathrm{Li}^{2}$ \\ Wenbo Zhao (iD ${ }^{2}$ \\ Yanru Chen ${ }^{2}$ \\ Hongli Shang ${ }^{2}$ \\ Min Zhang $\mathbb{D}^{3}$ \\ Jing Zheng ${ }^{4}$
}

'School of Nursing, Sun Yat-sen University, Guangzhou, People's Republic of China; ${ }^{2}$ Department of Nephrology, The Third Affiliated Hospital of Sun Yatsen University, Guangzhou, People's Republic of China; ${ }^{3}$ Department of Epidemiology and Health Statistics, School of Public Health, Guangdong Pharmaceutical University, Guangzhou, People's Republic of China; ${ }^{4}$ School of Nursing, Guangdong Pharmaceutical University, Guangzhou, People's Republic of China

*These authors contributed equally to this work
Correspondence: Jing Zheng

School of Nursing, Guangdong

Pharmaceutical University, Guangzhou,

Guangdong 510310, People's Republic of

China

Email zhengj38@gdpu.edu.cn
Background: Home blood pressure monitoring helps patients with chronic kidney disease to improve blood pressure control and can predict cardiovascular events, renal function progress, and risk of death. Few instruments are available to assess patient adherence to home blood pressure monitoring.

Objective: The aim of the study was to develop an instrument to evaluate home blood pressure monitoring adherence in patients with chronic kidney disease and test its reliability and validity. Methods: An item pool was formed for the Home Blood Pressure Monitoring Adherence Scale by literature review. Patients with chronic kidney disease $(n=436)$ were surveyed to assess item selection and examine item reliability and validity. Scale reliability was evaluated using internal, split-half, and test-retest reliability, while validity was assessed according to content, construct, and criterion validity.

Results: The scale comprising eight items was formed from the item pool and item selection. Cronbach's $\alpha$ was 0.906 , split-half reliability was 0.947 , and test-retest reliability was 0.716. Item-level and scale-level (both universal agreement and average) content validity indices were 1.00. According to the Self-Efficacy for Managing Chronic Disease 6 -item Scale, criterion validity for our scale was 0.251 . Exploratory factor analysis extracted one factor and the cumulative variance contribution rate was $61.568 \%$. Confirmatory factor analysis showed the model fit well $\left(X^{2}=50.125, d f=17, X^{2} / d f=2.949\right.$, root mean square error of approximation $=0.095$, confirmatory fit index $=0.970$ ).

Conclusion: The scale has good reliability and validity for patients with chronic kidney disease, representing an efficient instrument for clinical assessment of home blood pressure monitoring adherence.

Keywords: chronic kidney disease, home blood pressure monitoring, adherence, reliability, validity

\section{Introduction}

Chronic kidney disease (CKD) is a group of common chronic progressive diseases, characterised by deterioration of kidney structure and function. With CKD development, symptoms of multiple organ dysfunction occur. ${ }^{1}$ The total prevalence of CKD in Chinese adults was $10.8 \%$ in $2012 .^{2}$ Hypertension is common in patients with CKD. In 2009, the results of a survey conducted in 61 tertiary hospitals in 31 provinces in China showed that the prevalence of hypertension in non-dialysis $\mathrm{CKD}$ patients was $67.3 \%$, and hypertension prevalence increases with declining renal function; for patients with stage $5 \mathrm{CKD}$ (includes both dialysis and non-dialysis 
patients), the prevalence of hypertension can be as high as $91 \%{ }^{3}$ Hypertension is a major risk factor for CKD progression and cardiovascular diseases. The risk of cardiovascular diseases, including atherosclerosis and heart failure, as well as cardiovascular events and vascular death, increases significantly with elevated blood pressure (BP) in patients with CKD. ${ }^{4}$ Therefore, control of BP is particularly important in patients with CKD.

Administration of antihypertensive drugs is the main method of hypertension control in patients with CKD. ${ }^{5}$ In addition to medication, lifestyle improvements (healthy diet, weight control, no smoking, limited drinking, increased exercise, etc.) are also important for controlling BP in patients with CKD. ${ }^{6}$ Compared with the general hypertensive population, $\mathrm{BP}$ control rates in patients with $\mathrm{CKD}$ remain lower, despite increases in the types of antihypertensive drug available. $^{7}$ The treatment rate of hypertension in patients with CKD in China is $81.0 \%,{ }^{3}$ and patients who use 3 or $\geq 4$ antihypertensive drugs account for $21.1 \%$ and $10.9 \%$, respectively; ${ }^{8}$ however, $\mathrm{BP}$ control rates are only $33.1 \%$ $(<140 / 90 \mathrm{mmHg})$ and $14.1 \%(<130 / 80 \mathrm{mmHg}){ }^{3}$ Therefore, methods to increase patient awareness of and attention on BP, and help them effectively control their hypertension, are key and challenging for BP control.

BP monitoring has an important role in the diagnosis and treatment of hypertension. Patient BP is usually measured by a nurse or doctor in the office, and dose and choice of antihypertensive drugs and lifestyle improvements are determined based on these values. Compared with BP measured in the office, home BP monitoring (HBPM) can reflect patient BP levels under daily living conditions, and are conducive to improving BP control rates in patients with CKD. ${ }^{9}$ Moreover, HBPM is of extremely important prognostic value for cardiovascular events, renal function progression, and risk of death in patients with CKD. ${ }^{10}$ Additionally, with its advantages of simple operation, non-invasiveness, strong repeatability, and improved drug adherence, ${ }^{11,12}$ HBPM is recommended in the guidelines of the American, European, Japanese, and Chinese Societies of Hypertension. ${ }^{13-16}$ Further, these guidelines include recommendations on the frequency of HBPM and the method of BP measurement.

\section{Background}

Studies in the United States and Britain have reported that HBPM rates in patients with hypertension range from $30 \%$ to $49 \%,{ }^{17-19}$ and they show an increasing trend over time. ${ }^{19}$ In contrast, HBPM rates in patients with hypertension in China are as high as $79.3 \% .^{20}$ The rate of HBPM has become a focus of academic attention; ${ }^{17-21}$ however, to fully benefit from the clinical value of HBPM, patients need to be able to measure BP at home accurately, regularly, and over extended periods. Nevertheless, HBPM has not been studied in depth as a behaviour. Most studies have simply evaluated rates of HBPM in patients, with little attention paid to the specifics of how they monitor their BP.

Whether patients follow the instructions of their healthcare professionals to monitor BP at home is a crucial issue. Liu et al showed that $30.5 \%$ of patients with hypertension monitored BP at home daily in China, while $28.1 \%$ of patients only conducted measurements when they experienced specific symptoms. ${ }^{20}$ In contrast, a UK survey showed that only $14 \%$ of patients with hypertension selfmonitored BP at least once per day. ${ }^{17}$ Further, a study by Milot et al showed that $48.1 \%$ (in 2010) and 52.1\% (in 2014) of patients took a 5-minute break before HBPM, ${ }^{22}$ while Liu et al showed that $33.9 \%$ of patients only measured BP once on each occasion. ${ }^{20}$ These findings suggest that HBPM reliability requires improvement.

To date, few studies on patient adherence to HBPM have been conducted, and there is a lack of instruments with good reliability and validity. Here, HBPM adherence refers to patient $\mathrm{BP}$ monitoring behaviour, according to their physician's advice; specifically, it includes regular, long-term, and accurate BP measurement, including tracking the time of BP monitoring, and correctly performing BP measurement. In this study, we aimed to develop a Home Blood Pressure Monitoring Adherence Scale (HBPMAS) for patients with CKD and test the reliability and validity of this instrument, to provide an efficient instrument for clinical professionals assessing HBPM adherence in patients with CKD.

\section{Methods}

\section{Item Pool Formation}

To ensure the clinical value of HBPM data, regular, longterm, and accurate BP measurement at home are fundamental requirements. Literature review was conducted focusing on the "2018 Chinese Guidelines for the Management of Hypertension", 16 "Home BP Monitoring: A Consensus Document", ${ }^{23}$ and other relevant guidelines worldwide. Through the literature review and discussion and revision by the research group, an initial HBPMAS item pool comprising 10 items was generated, including timing of HBPM (3 items; for example, "I measure my blood pressure at home in the morning and evening"); 
precautions for BP measurement (7 items; for example, "I'll take a 5-minute break and then measure my blood pressure", "I keep track of my blood pressure readings", and "I will provide the medical staff with a complete blood pressure record").

\section{Expert Consultation}

Two rounds of consultation with eight experts in nephrology, cardiology, nursing, and education were conducted. The experts comprised two males and six females, aged 24-54 (37.25 \pm 9.13$)$ years old, who had worked in their role for an average of $13.00 \pm 11.21$ years, and four of them had master's or higher degrees. The experts were invited to evaluate the importance, relevance, and linguistic expression of each item. The importance was rated using a 5-point Likert scale (very important, important, moderately important, unimportant, and very unimportant). The relevance was rated using a 4-point Likert scale (completely relevance, relatively relevance, not relevance, and completely not relevance). The active coefficients of the experts in the two rounds were $100 \%$. The expert authority coefficient was 0.84 , and the expert coordination coefficients were 0.310 and 1.000, respectively, for each round. A full-score ratio (the percentage of experts who give full marks for item importance) $\geq 50 \%$, with an average score of importance assignment $\geq 4.00$, and an item-level content validity index (I-CVI) $\geq 0.78$, was considered the item selection standard. ${ }^{24}$ According to the results of expert consultation and discussion by the research group, the item "I measure my blood pressure at home in the morning and evening" was divided into two items ("I measure my blood pressure at home in the morning" and "I measure my blood pressure at home in the evening"). At the same time, three items were inappropriate for self-report scale and they were deleted in the first round of experts' panel consultation. Finally, a draft HBPMAS for patients with CKD, including eight items, was formed.

\section{Psychometric Tests of the Draft HBPMAS Participants}

A survey was conducted in the nephrology departments in two tertiary hospitals in Guangdong province from March to October 2019, using convenience sampling. Patient inclusion criteria were: (1) diagnosed with CKD according to the Guidelines of Kidney Disease: Improving Global Outcomes (KDIGO); (2) met the diagnostic criteria of hypertension in the 2018 Chinese Guidelines for the Management of Hypertension: systolic BP $\geq 140 \mathrm{mmHg}$ and/or diastolic BP $\geq 90 \mathrm{mmHg}$ without taking antihypertensive drugs; (3) age $\geq 18$ years old; and (4) agreed to participate in this study. Patient exclusion criteria were: (1) dyskinesia of the upper limbs, (2) upper-extremity amputations, (3) high anxiety or history of mental disorders, (4) cognitive impairment, and (5) hearing impairment. This study received appropriate approval from the ethics and academic committees of the university. All participants signed their informed consent prior to their inclusion in the study.

\section{Instrument}

Patient general characteristics questionnaires were used to investigate the patient demographic and sociological information, including sex, age, and education level, as well as disease-related information, such as stage of CKD.

The first draft of the HBPMAS, comprising eight items, was employed to assess patients' adherence to HBPM during last month. The HBPMAS is a self-report scale that uses a 5-point Likert rating system, involving: never $(0$ times in the past month $)=1$, occasionally $(1-3$ times $/$ month $)=2$, sometimes (once a week on average $)=$ 3 , often (average a few times a week but not every day) $=$ 4 , and always (every day) $=5$. Total scores ranged from 8 to 40 , with higher scores indicating better adherence.

The Self-Efficacy for Managing Chronic Disease 6-item Scale, developed by Lorig et al, ${ }^{25}$ was used as the criterion instrument to test criterion validity. This scale consists of six items, where each item scores 1-10 points and is used to measure levels of self-efficacy in patients with chronic diseases; the average score of the items indicates the level of self-efficacy, with higher scores representing superior self-efficacy.

\section{Data Collection}

Questionnaires were distributed face-to-face by the investigator, after an explanation of the purpose of the survey to patients and their families, and after obtaining informed consent. All questionnaires were completed by the patients themselves, or with assistance from the investigator if the patient did not understand the questionnaire well or had a physical disability. The investigator collected the questionnaires immediately after patients filled them out, and then examined the completeness of the questionnaires.

\section{Criteria for Item Analysis and Selection}

In this study, frequency distribution analysis of the item options, coefficient of variation $(\mathrm{CV})$, critical ratio (CR), item-total correlation, corrected item-total correlation 
(CITC), Cronbach's $\alpha$, communalities value, and factor loading were used to analyse and screen the items.

Criteria for item deletion were: (1) item with $>80 \%$ frequency distribution for a single option; ${ }^{26}$ (2) $\mathrm{CV}<0.15 ;^{27}$ (3) $\mathrm{CR}<3 ;^{27}$ (4) item-total correlation coefficient $<0.4$, or item with no statistical significance, ${ }^{27}$ (5) CITC $<0.4$, or item with no statistical significance, ${ }^{27}$ (6) overall Cronbach's $\alpha$ for the scale after item deletion is higher than the original; ${ }^{27}$ (7) communalities value $<0.20 ;{ }^{27}$ and (8) factor loading $<0.45{ }^{27}$ Items which met five or more of the above criteria could be deleted. ${ }^{28}$

\section{Scale Reliability and Validity Test}

Internal consistency reliability, split-half reliability, and test-retest reliability were used to test the scale reliability. Cronbach's $\alpha$ was used to test internal consistency, with a value $>0.7$ considered acceptable. ${ }^{29}$ The split-half reliability of the scale was tested using the odd-even method. Regarding test-retest reliability, 20 patients were randomly selected, with a mean interval of 12 days followed by a second measurement; test-retest reliability values $>0.7$ were considered acceptable. ${ }^{27}$

Content, construct, and criterion validity were used to test the validity of the scale. Content validity was evaluated by I-CVI, scale-level content validity index/universal agreement (S-CVI/UA), and scale-level content validity index/average (S-CVI/AVE). The content validity of the scale was considered good if I-CVI was $\geq 0.78$, S-CVI/UA $\geq 0.8$, and $\mathrm{S}-\mathrm{CVI} / \mathrm{AVE} \geq 0.9$. $^{24}$ The construct validity of the scale was evaluated by exploratory and confirmatory factor analyses. If the cumulative explanatory variation of common factors extracted in the exploratory factor analysis was $>50 \%,{ }^{27} X^{2} / d f$ in the confirmatory factor analysis was $<3$, the root mean square error of approximation (RMSEA) was $<0.1$, and the confirmatory fit index (CFI) was $>0.9,^{30}$ the construct validity of the scale was considered to be good. The Self-Efficacy for Managing Chronic Disease 6-item Scale was used as the criterion for evaluation of the HBPMAS, with the correlation coefficient of scores from the two scales used to assess criterion validity.

\section{Statistical Analysis}

Data were entered and checked by two researchers, and SPSS 20.0 and Amos 23.0 were used for statistical analyses. The database was divided into two datasets randomly including training dataset and confirmatory dataset. The training dataset $(n=218)$ was used for item analysis and selection and exploratory factor analysis, while the confirmatory dataset $(n=218)$ was used for confirmatory factor analysis, scale reliability testing, and validity testing.

\section{Results}

\section{Characteristics of the Participants}

A total of 436 patients with CKD stage 1-5, aged $52.77 \pm$ 14.45 years, were enrolled in this study. The average office systolic blood pressure was $147.50 \pm 21.19 \mathrm{mmHg}$ and the average office diastolic blood pressure was 87.30 $\pm 14.22 \mathrm{mmHg}$. And $82.1 \%$ of patients received antihypertensive drug therapy. More than half of the patients were treated with a combination of two or more antihypertensive drugs, including angiotensin-converting enzyme inhibitors (ACEI), angiotensin receptor blockers (ARB), calcium-channel blockers (CCB), beta blockers, etc. A total of 436 questionnaires were issued, and 436 were effectively collected, representing an effective response rate of $100 \%$. Participant characteristics are presented in Table 1.

\section{Item Analysis and Selection}

The frequency distribution of the options for each item of the HBPMAS for patients with CKD is presented in Table 2. After analysis, no items had $>80 \%$ frequency distribution for a single option. Cronbach's $\alpha$ for the eight items was 0.922 . No items were deleted after the analysis according to the item deletion criteria. The results of analysis of the items are shown in Table 3.

\section{Scale Reliability and Validity Reliability}

Cronbach's $\alpha$ for this scale was 0.906 and the split-half reliability was $0.947(p<0.001)$. The test-retest reliability (the correlation coefficient of the total score measured at two time points) was 0.716 , which was statistically significant $(p<0.001)$.

\section{Validity}

The I-CVI for the eight items in this study was 1.00 , while the S-CVI/UA and S-CVI/AVE were also both 1.00. The Kaiser-Meyer-Olkin index was 0.874 and the Bartlett spherical test chi-square value reached statistical significance $\left(X^{2}=1156.525, p<0.001\right)$, indicating that the data were suitable for factor analysis. After principal component analysis and varimax rotation, one factor was extracted, whose eigenvalue for the initial load matrix 
Table I Participant Characteristics $(n=436)$

\begin{tabular}{|c|c|c|c|c|c|}
\hline Characteristics & $\mathbf{n}$ & $\%$ & Characteristics & $\mathbf{n}$ & $\%$ \\
\hline Sex & & & Office systolic blood pressure & & \\
\hline Male & 284 & 65.1 & $100 \sim 139 \mathrm{mmHg}$ & 158 & 36.2 \\
\hline Female & 152 & 34.9 & $140 \sim 159 \mathrm{mmHg}$ & 163 & 37.4 \\
\hline Age (years) & & & $160 \sim 179 \mathrm{mmHg}$ & 86 & 19.7 \\
\hline 20 44 & 124 & 28.4 & $180 \sim 247 \mathrm{mmHg}$ & 29 & 6.7 \\
\hline $45 \sim 59$ & 153 & 35.1 & Office diastolic blood pressure & & \\
\hline $60 \sim 74$ & 138 & 31.7 & $60 \sim 89 \mathrm{mmHg}$ & 252 & 57.8 \\
\hline $75 \sim 87$ & 21 & 4.8 & $90 \sim 99 \mathrm{mmHg}$ & 97 & 22.3 \\
\hline Education & & & $100 \sim 109 \mathrm{mmHg}$ & 59 & 13.5 \\
\hline $\begin{array}{l}\text { Primary school } \\
\text { or below }\end{array}$ & 114 & 26.1 & $110 \sim 135 \mathrm{mmHg}$ & 28 & 6.4 \\
\hline Junior school & 127 & 29.1 & Number of antihypertensive drugs & & \\
\hline High school & 111 & 25.5 & 0 & 78 & 17.9 \\
\hline College or above & 84 & 19.3 & 1 & 110 & 25.2 \\
\hline Occupation status & & & 2 & 117 & 26.8 \\
\hline Unemployed & 190 & 43.6 & $3 \sim 5$ & $13 \mid$ & 30.1 \\
\hline Employed & 139 & 31.9 & & & \\
\hline Retired & 107 & 24.5 & & & \\
\hline Stage of CKD* & & & & & \\
\hline CKD-I & 17 & 3.9 & & & \\
\hline CKD-2 & 13 & 3.0 & & & \\
\hline CKD-3a/CKD-3b & 21 & 4.8 & & & \\
\hline CKD-4 & 9 & 2.1 & & & \\
\hline $\begin{array}{l}\text { CKD-5 } \\
\text { (non-dialysis) }\end{array}$ & 32 & 7.3 & & & \\
\hline Haemodialysis & 323 & 74.1 & & & \\
\hline Peritoneal dialysis & 21 & 4.8 & & & \\
\hline
\end{tabular}

Note: *The stage of chronic kidney disease (CKD) was stratified with estimated glomerular filtration rate (eGFR) according to the Guidelines of Kidney Disease: Improving Global Outcomes.

was $>1$, and which accounted for $61.568 \%$ of the total variance (Table 4). The ratio of the first eigenvalue to the second eigenvalue was $>2$, supporting a single-factor structure. All items had factor loads $>0.4$ (items 1-8: $0.850,0.771,0.699,0.783,0.571,0.832,0.857$, and 0.868 , respectively).

In the exploratory factor analysis, a total of one factor and eight items were formed with the training dataset, and the construct validity of the scale was further verified by confirmatory factor analysis with the confirmatory dataset. The model fitting indices were as follows: $X^{2}=153.890$ $(p<0.001), d f=20, X^{2} / d f=7.694$, RMSEA $=0.176$, and $\mathrm{CFI}=0.880$.

The model was further modified based on the modification index and discussion within the research group. According to the modification index, given that items 1 and 2 were morning and evening BP measurements, items 4 and 5 were about how to take BP measurements, and items 3 and 8 referred to situations in which BP needs to be measured, a covariant relationship was established among the error values of these items. The modified model fitting indices were as follows: $X^{2}$ $=50.125(p<0.001), d f=17, X^{2} / d f=2.949$, RMSEA $=0.075$, and CFI $=0.970$. The model structure is shown in Figure 1.

The correlation coefficients between items in the HBPMAS for patients with CKD were in the range 0.314-0.820 $(p<0.001)$. Correlation coefficients between the eight items and the total score were 0.619-0.857 $(p<0.001)$ (Table 5). The correlation coefficient between the HBPMAS and the Self-Efficacy for Managing Chronic Disease 6-item Scale was $0.251(p<0.001)$.

\section{The Scores of HBPMAS for Non-Dialysis and Dialysis Patients}

The total score of the HBPMAS in the last month of nondialysis patients was $24.41 \pm 8.33$ points. While the total score of the HBPMAS of dialysis patients was $25.17 \pm 8.69$ points. There was no statistically significant difference between the two groups in total score of the HBPMAS $(Z=1.092, p=0.275)$. For non-dialysis patients, the highest score was $3.60 \pm 1.32$ on item "I was able to adjust my blood pressure measurement as advised by the medical personnel". For dialysis patients, the highest score was $3.63 \pm 1.33$ on item "When I feel discomfort (such as dizziness, headache, and stiff neck), I'll measure my blood pressure". For both non-dialysis and dialysis patients, the item with the lowest score was "I will take the second measurement at an interval of 1-2 minutes". The scores of each item are shown in Table 6.

\section{Discussion}

HBPM has been proven to be of great value for BP control and prognosis in patients with CKD. ${ }^{9-12}$ Regular, accurate, and long-term measurement of BP at home is important for the clinical value of HBPM. The Japanese Society of Hypertension recommended that home BP should be monitored 1-3 times in both the morning and evening, in a sitting position after 1-2 minutes of rest, and BP should be measured over as long a period as possible. ${ }^{13}$ The European Society of Hypertension recommended that HBPM should be performed in the morning (before drug intake if treated) and in the evening, and that treated hypertensive patients may also perform regular HBPM as long-term follow-up. ${ }^{15}$ Based on the guidelines of various countries and the Chinese population's lifestyle, Chinese 
Table 2 Frequency Distribution for Each Option of Each Item (n/\%)

\begin{tabular}{|c|c|c|c|c|c|}
\hline \multirow[b]{2}{*}{ Item } & \multicolumn{5}{|c|}{ Training Dataset $(n=2 \mid 8)$} \\
\hline & Never & Occasionally & Sometimes & Often & Always \\
\hline I. I measure my blood pressure at home in the morning. & $56(25.7)$ & $45(20.6)$ & $18(8.3)$ & $51(23.4)$ & $48(22.0)$ \\
\hline 2. I measure my blood pressure at home in the evening. & $68(31.2)$ & $57(26.1)$ & $16(7.3)$ & $40(18.3)$ & $37(17.0)$ \\
\hline $\begin{array}{l}\text { 3. When I feel discomfort (such as dizziness, headache, and stiff neck), I will } \\
\text { measure my blood pressure. }\end{array}$ & $34(15.6)$ & $19(8.7)$ & $14(6.4)$ & $92(42.2)$ & $59(27.1)$ \\
\hline 4. I will take a 5-minute break and then measure my blood pressure. & $48(22.0)$ & $29(13.3)$ & $27(12.4)$ & $69(31.7)$ & $45(20.6)$ \\
\hline 5. I will take the second measurement at an interval of $\mathrm{I}-2$ minutes. & $79(36.2)$ & $79(36.2)$ & $21(9.6)$ & $21(9.6)$ & $18(8.3)$ \\
\hline $\begin{array}{l}\text { 6. I was able to adjust my blood pressure measurement as advised by the } \\
\text { medical personnel. }\end{array}$ & $34(15.6)$ & $19(8.7)$ & $32(14.7)$ & $96(44.0)$ & $37(17.0)$ \\
\hline 7. I monitor my blood pressure at home even when I am busy. & $40(18.3)$ & $52(23.9)$ & $22(10.1)$ & $73(33.5)$ & $31(14.2)$ \\
\hline $\begin{array}{l}\text { 8. When my blood pressure is well controlled, I will still monitor my blood } \\
\text { pressure at home. }\end{array}$ & $43(19.7)$ & $50(22.9)$ & $19(8.7)$ & $71(32.6)$ & $35(16.1)$ \\
\hline
\end{tabular}

Table 3 Results of Item Analysis $(n=218)$

\begin{tabular}{|c|c|c|c|c|c|c|c|c|c|c|}
\hline Item & $\bar{X}$ & $\mathbf{s}$ & CV & CR & $\begin{array}{l}\text { Item-Total } \\
\text { Correlation }\end{array}$ & CITC & $\begin{array}{l}\text { Cronbach's } \alpha \text { if } \\
\text { Item is Deleted }^{\#}\end{array}$ & Communalities & $\begin{array}{l}\text { Factor } \\
\text { Loading }\end{array}$ & $\begin{array}{l}\text { Substandard } \\
\text { Quantity }\end{array}$ \\
\hline I & 2.95 & 1.535 & 0.520 & $27.267 * *$ & $0.83 I^{* *}$ & 0.763 & 0.892 & 0.693 & 0.832 & 0 \\
\hline 2 & 2.64 & 1.500 & 0.568 & $19.145^{* *}$ & $0.779 * *$ & 0.696 & 0.898 & 0.595 & $0.77 \mid$ & 0 \\
\hline 3 & 3.56 & 1.381 & 0.388 & $9.932 * *$ & $0.706 * *$ & 0.613 & 0.904 & 0.489 & 0.699 & 0 \\
\hline 4 & 3.16 & 1.463 & 0.463 & $19.312 * *$ & $0.790 * *$ & 0.712 & 0.896 & 0.613 & 0.783 & 0 \\
\hline 5 & 2.17 & 1.251 & 0.576 & $9.016 * *$ & $\left.0.59\right|^{* *}$ & 0.486 & 0.914 & 0.326 & $0.57 \mid$ & I \\
\hline 6 & 3.38 & 1.301 & 0.385 & $16.587^{* *}$ & $0.84 I^{* *}$ & 0.788 & 0.890 & 0.723 & 0.850 & 0 \\
\hline 7 & 3.01 & 1.373 & 0.456 & $20.174 * *$ & $0.843^{* *}$ & 0.787 & 0.890 & 0.734 & 0.857 & 0 \\
\hline 8 & 3.02 & 1.412 & 0.468 & $23.976 * *$ & $0.856 * *$ & 0.802 & 0.888 & 0.753 & 0.868 & 0 \\
\hline
\end{tabular}

Notes: ${ }^{\#}$ Cronbach's $\alpha$ for the eight items was $0.922 ; * * p<0.001$.

Abbreviations: CV, coefficient of variation; CR, critical ratio; CITC, corrected item-total correlation.

Table 4 Total Variance Explained

\begin{tabular}{|c|c|c|c|c|c|c|}
\hline \multirow[t]{2}{*}{ Component } & \multicolumn{3}{|c|}{ Initial Eigenvalues } & \multicolumn{3}{|c|}{ Extracted Sum of Squared Loadings } \\
\hline & Total & Variance (\%) & Cumulative (\%) & Total & Variance (\%) & Cumulative (\%) \\
\hline I & 4.925 & 61.568 & 61.568 & 4.925 & 61.568 & 61.568 \\
\hline 2 & 0.874 & 10.921 & 72.489 & & & \\
\hline 3 & 0.658 & 8.227 & 80.715 & & & \\
\hline 4 & 0.551 & 6.883 & 87.598 & & & \\
\hline 5 & 0.375 & 4.689 & 92.287 & & & \\
\hline 6 & 0.257 & 3.211 & 95.498 & & & \\
\hline 7 & 0.234 & 2.921 & 98.419 & & & \\
\hline 8 & 0.126 & $|.58|$ & 100 & & & \\
\hline
\end{tabular}

experts suggested that Chinese patients whose BP is not in the healthy range should have their BP measured in the morning and evening every day, 2-3 times on each occasion, with an interval of 1 minute, and rest for 5-10 minutes before measurements are taken; ${ }^{16}$ however, whether patients actually follow these guidelines has not been thoroughly studied. Therefore, HBPM adherence requires attention.
Despite the high attention paid to the academic value of HBPM and now clinical medical personnel are also in the emphasis and promotion of HBPM, instruments for assessing patients' HBPM behavior, especially HBPM adherence, are limited. Milot et al used a questionnaire to evaluate the accuracy of patient HBPM, in terms of measuring equipment, technology, recording, and reporting of measurement results; however, ${ }^{22}$ the questions used in their investigation 


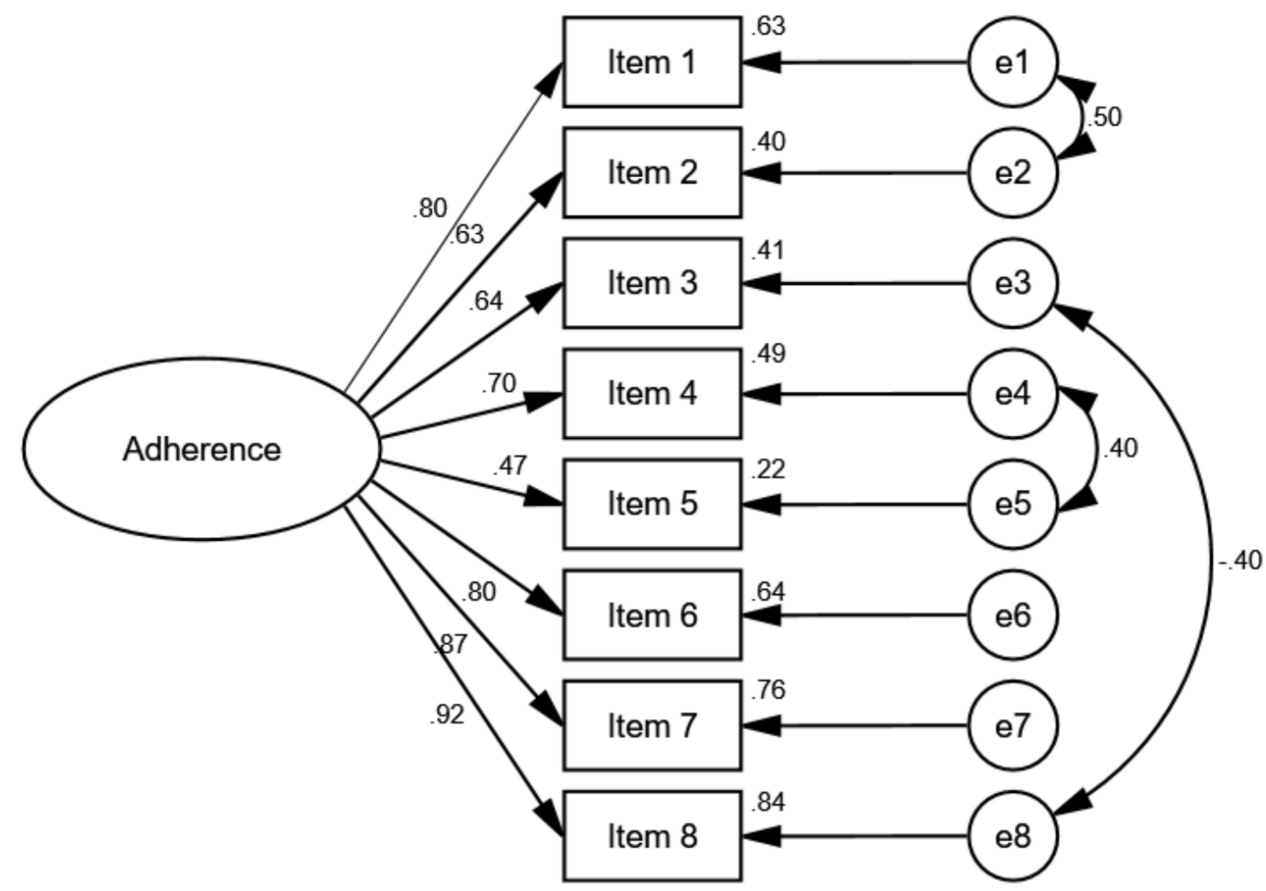

Figure I Confirmatory factor analysis model.

about the use of monitoring equipment provided by clinical pharmacists do not apply to the situation in China, and there are two or three measurement technology points in a question (like seated, legs not crossed and back supported), which is difficult for the patient to answer. Liu et al designed 10 questions to investigate ownership and types of HBPM devices, as well as HBPM awareness and behaviour in China; ${ }^{20}$ however, the questionnaire lacked investigation of BP measurement methods. Further, instruments with good reliability and validity are lacking.

This is the first study that we know to develop the measurement instruments of adherence for HBPM and to evaluate the reliability and validity. Based on a review of the literature (including relevant guidelines), our research group developed a scale item pool focusing patients' adherence behaviour regarding HBPM. The draft scale was formed through two rounds of expert consultation, where all the experts actively participated in the consultation and showed high levels of experience and authority. There was a high degree of consistency and coordination among the expert opinions; thus, the results of the expert consultation are reliable. Thereafter, questionnaires were distributed among patients with $\mathrm{CKD}$, and the scale items were analysed and screened using a variety of methods.

The result of item analysis showed that the scale items were highly sensitive, differentiated, and representative. We analysed the data of 436 patients with CKD, which covered all stages of CKD and the main alternative

Table 5 Correlation Analysis Between Items and Between Each Item and the Total

\begin{tabular}{|c|c|c|c|c|c|c|c|c|}
\hline Variables & Item I & Item 2 & Item 3 & Item 4 & Item 5 & Item 6 & Item 7 & Item 8 \\
\hline Item I & I & & & & & & & \\
\hline Item 2 & $0.736 * *$ & I & & & & & & \\
\hline Item 3 & $0.513^{* *}$ & $0.476 * *$ & I & & & & & \\
\hline Item 4 & $0.618^{* *}$ & $0.544 * *$ & $0.472^{* *}$ & I & & & & \\
\hline Item 5 & $0.330 * *$ & $0.404 * *$ & $0.314^{* *}$ & $0.583 * *$ & I & & & \\
\hline Item 6 & $0.601 * *$ & $0.495 * *$ & $0.560 * *$ & $0.563^{* *}$ & $0.390 * *$ & I & & \\
\hline Item 7 & $0.663 * *$ & $0.528 * *$ & $0.514^{* *}$ & $0.575^{* *}$ & $0.403^{* *}$ & $0.742 * *$ & I & \\
\hline Item 8 & $0.746 * *$ & $0.552 * *$ & $0.467^{* *}$ & $0.626^{* *}$ & $0.430 * *$ & $0.703 * *$ & $0.820^{* *}$ & I \\
\hline Total & $0.844 * *$ & $0.774 * *$ & $0.688^{* *}$ & $0.80 I^{* *}$ & $0.619 * *$ & $0.800 * *$ & $0.838^{* *}$ & $0.857^{* *}$ \\
\hline
\end{tabular}

Note: $* * p<0.001$. 
Table 6 The Scores of HBPMAS for Non-Dialysis and Dialysis Patients

\begin{tabular}{|c|c|c|c|c|c|c|c|c|c|c|}
\hline \multirow[b]{2}{*}{ Item } & \multirow[b]{2}{*}{ Grading Range } & \multicolumn{3}{|c|}{$\begin{array}{l}\text { Non-Dialysis Patients } \\
(n=92)\end{array}$} & \multicolumn{3}{|c|}{$\begin{array}{l}\text { Dialysis Patients } \\
(n=344)\end{array}$} & \multicolumn{3}{|l|}{$\begin{array}{l}\text { All Patients } \\
(n=436)\end{array}$} \\
\hline & & Score Range & $\bar{X}$ & $S$ & Score Range & $\bar{X}$ & $S$ & Score Range & $\bar{X}$ & $S$ \\
\hline Item I & $1 \sim 5$ & $1 \sim 5$ & 3.18 & 1.33 & $1 \sim 5$ & 3.15 & 1.54 & $1 \sim 5$ & 3.16 & 1.50 \\
\hline Item 2 & $1 \sim 5$ & $1 \sim 5$ & 2.47 & 1.31 & $1 \sim 5$ & 2.91 & 1.55 & $1 \sim 5$ & 2.82 & 1.51 \\
\hline Item 3 & $1 \sim 5$ & $1 \sim 5$ & 3.45 & 1.35 & $1 \sim 5$ & 3.63 & 1.33 & $1 \sim 5$ & 3.59 & 1.33 \\
\hline Item 4 & $1 \sim 5$ & $1 \sim 5$ & 2.98 & 1.56 & $1 \sim 5$ & 3.32 & 1.36 & $1 \sim 5$ & 3.25 & 1.41 \\
\hline Item 5 & $1 \sim 5$ & $\mid \sim 5$ & 2.13 & 1.34 & $1 \sim 5$ & 2.38 & 1.29 & $1 \sim 5$ & 2.33 & 1.30 \\
\hline Item 6 & $\mathrm{I} \sim 5$ & $1 \sim 5$ & 3.60 & 1.32 & $1 \sim 5$ & 3.44 & 1.20 & $1 \sim 5$ & 3.47 & 1.22 \\
\hline Item 7 & $1 \sim 5$ & $1 \sim 5$ & 3.27 & 1.42 & $1 \sim 5$ & 3.17 & $\mathrm{I} .34$ & $1 \sim 5$ & 3.19 & 1.36 \\
\hline Item 8 & $1 \sim 5$ & $1 \sim 5$ & 3.34 & 1.41 & $1 \sim 5$ & 3.17 & 1.38 & $1 \sim 5$ & 3.20 & 1.39 \\
\hline Total & $8 \sim 40$ & $8 \sim 40$ & 24.41 & 8.33 & $8 \sim 40$ & 25.17 & 8.69 & $8 \sim 40$ & 25.01 & 8.61 \\
\hline
\end{tabular}

Abbreviation: HBPMAS, Home Blood Pressure Monitoring Adherence Scale.

treatment of end-stage renal disease (ESRD), so the measurement results were representative and could reflect the HBPM adherence of patients with CKD.

The HBPMAS showed good reliability for patients with CKD. According to DeVellis, a Cronbach's $\alpha$ between 0.65 and 0.70 is the minimum acceptable value, while between 0.70 and 0.80 is quite good, and between 0.80 and 0.90 is very good. ${ }^{29}$ The Cronbach's $\alpha$ for our scale was 0.906 , while the split-half reliability was 0.947 , indicating that the internal consistency of the scale was good. The test-retest reliability of the scale was 0.716 $(>0.7),{ }^{27}$ demonstrating that the scale has good crosstime stability. Overall, the scale has good reliability and the measurement results were consistent and stable.

The HBPMAS for patients with CKD also exhibited good content validity, with the I-CVI for the eight items, $\mathrm{S}-\mathrm{CVI} / \mathrm{UA}$, and S-CVI/AVE all being 1.00 (I-CVI $\geq 0.78$, $\mathrm{S}-\mathrm{CVI} / \mathrm{UA} \geq 0.8$, and $\mathrm{S}-\mathrm{CVI} / \mathrm{AVE} \geq 0.9$ all indicate $\mathrm{good}$ content validity). ${ }^{24}$ The good content validity of the scale indicated that the content actually measured by the scale was highly consistent with the content to be measured. Exploratory factor analysis showed that the factor loading values of the eight items in the scale were all $>0.40$, and the cumulative variance contribution rate of common factors was $61.568 \%$. The results of the confirmatory factor analysis showed that $X^{2} / d f$ was 2.949, RMSEA was 0.095 , and CFI was 0.970 , indicating that the model fits well and the questionnaire has good construct validity. These results show that the scale has good validity and the measurement results are accurate and reliable.

In addition to internal validity, external validity is also an important factor regarding scale validity. Curtin et al demonstrated that higher self-efficacy was associated with increased self-management behaviours, including medication adherence, in patients with $\mathrm{CKD},{ }^{31}$ so in this study, the Self-Efficacy for Managing Chronic Disease 6-item Scale was used as the criterion. The results showed that the HBPMAS had good criterion validity.

According to the guidelines and previous reports, about $60 \%$ of hypertensive patients performed HBPM, but the accuracy of blood pressure measurement needs to be improved. $^{20-22}$ However, the adherence of HBPM in patients with CKD is still not explored in depth. This study is the first to investigate the current situation of HBPM adherence among CKD patients in China. The results of this study showed that the regularity and accuracy of HBPM of CKD patients was as undesirable as that in patients with hypertension. For the number of measurements on each occasion, Liu et al showed that a third of hypertensive patients only measured $\mathrm{BP}$ once on each occasion. ${ }^{20}$ In this study, the score of item "I will take the second measurement at an interval of 1-2 minutes" was the lowest for both dialysis and non-dialysis patients, which was in line with previous study on HBPM adherence in hypertensive patients. Regarding attention points during measurement, it was found that both dialysis and non-dialysis patients did not score well on the item "I'll take a 5-minute break and then measure my blood pressure", which was consistent with Milot and colleagues' study with hypertensive patients in which only about $50 \%$ of patients took a 5-minute break before HBPM. ${ }^{22}$ This suggests that health education related to HBPM for CKD patients is in urgent need and the details of how to perform BP measurement correctly should be strengthened during patient education. 
In this study, patients' adherence with HBPM was investigated from two aspects: tracking the time of $\mathrm{BP}$ monitoring, and correctly performing BP measurement, which specified the details of HBPM adherence, and is helpful for individual targeted guidance after assessment. This scale helps to quantitatively evaluate patients' adherence to HBPM. It can be used in future in-depth analysis of adherence behavior and blood pressure control, as well as the association of long-term outcomes (such as cardiovascular events) in patients.

This study has several limitations. First, the HBPMAS is a self-report scale; therefore, there may be reporting bias and it is necessary to consider objective indicators of HBPM adherence in future research. Second, although patients with stage 1-5 CKD were enrolled, the participants were mainly on haemodialysis, so the sample may not be sufficiently representative of patients with CKD not undergoing dialysis or those undergoing peritoneal dialysis. Moreover, investigations were conducted only in two tertiary hospitals, which may limit the wider applicability of the findings. In future research, the representativeness of the included patients (with all stages of CKD) should be improved.

\section{Conclusion}

The HBPMAS for patients with CKD compiled in this study includes eight items with good reliability and validity, and the items are simple and easy to understand. The instrument is suitable for clinical professionals to evaluate HBPM adherence among patients, and it provides a means of evaluation for intervention trials.

\section{Relevance for Clinical Practice}

This study provides a sensitive and reliable quantitative assessment instrument for the specific adherence behavior of HBPM. It is suitable for rapid evaluation of HBPM behavior of CKD patients by medical personnel. Not only that the content of the items can also be used for non-CKD patients. During the clinical implementation of HBPM, healthcare professionals can use this instrument to assess patients' HBPM performance, and according to the evaluation results to give tailored guidance.

\section{Ethics Approval}

This study was approved by the ethics and academic committee of Sun Yat-sen University in accordance with the Declaration of Helsinki.

\section{Acknowledgments}

We sincerely thank all the participants and health professionals who participated in this research.

\section{Authorship}

All authors made a significant contribution to the work reported, whether that is in the conception, study design, execution, acquisition of data, analysis and interpretation, or in all these areas; took part in drafting, revising or critically reviewing the article; gave final approval of the version to be published; have agreed on the journal to which the article has been submitted; and agree to be accountable for all aspects of the work.

\section{Funding}

The study was supported by Nature Science Foundation of Guangdong (No. 2018A030313514) and Science and Technology Planning Project of Guangdong (No. 2017ZC0028).

\section{Disclosure}

Jing Zheng reports grants from Guangdong scientific foundation committee, during the conduct of the study. The authors declare no other potential conflicts of interest relating to this work.

\section{References}

1. Chen YP, Yu XQ. Nephrology. Beijing: People's Medical Publishing House; 2015.

2. Zhang L, Wang F, Wang L, et al. Prevalence of chronic kidney disease in China: a cross-sectional survey. Lancet. 2012;379:815-822. doi:10.1016/S0140-6736(12)60033-6

3. Zheng Y, Cai GY, Chen XM, et al. Prevalence, awareness, treatment, and control of hypertension in the non-dialysis chronic kidney disease patients. Chin Med J. 2013;126:2276-2280.

4. Sarafidis PA, Li S, Chen SC, et al. Hypertension awareness, treatment, and control in chronic kidney disease. Am J Med. 2008;121:332-340. doi:10.1016/j.amjmed.2007.11.025

5. Kidney Disease Outcomes Quality Initiative. K/DOQI clinical practice guidelines on hypertension and antihypertensive agents in chronic kidney disease. Am J Kidney Dis. 2004;43:S1-290.

6. Eskridge MS. Hypertension and chronic kidney disease: the role of lifestyle modification and medication management. Nephrol Nurs J. 2010;37:55.

7. Tanner RM, Calhoun DA, Bell EK, et al. Prevalence of apparent treatment-resistant hypertension among individuals with CKD. Clin J Am Soc Nephrol. 2013;8:1583-1590. doi:10.2215/CJN.00550113

8. Zheng Y, Cai G, Zhang X, Chen X. 472 prevalence, treatment and control of hypertension in patients with chronic kidney disease: results form the inpatients in the department of nephrology study (IDNS). J Hypertens. 2012;30:e140. doi:10.1097/01.hjh.0000420327.01701.eb

9. Rifkin DE, Abdelmalek JA, Miracle CM, et al. Linking clinic and home: a randomized, controlled clinical effectiveness trial of real-time, wireless blood pressure monitoring for older patients with kidney disease and hypertension. Blood Press Monit. 2013;18:8-15. doi:10.1097/MBP.0b013e32835d126c 
10. Agarwal R, Peixoto AJ, Santos SF, Zoccali C. Out-of-office blood pressure monitoring in chronic kidney disease. Blood Press Monit. 2009;14:2-11. doi:10.1097/MBP.0b013e3283262f58

11. Doyle-Campbell C. European Society of Hypertension and European Society of Cardiology guidelines and the muted enthusiasm for home blood pressure monitoring. Hypertension. 2014;63:e5. doi:10.1161/ HYPERTENSIONAHA.113.02286

12. Ma R, Wang Q, Li N, et al. Home blood pressure monitoring improved safety in patients with severe hypertension. J Hypertens. 2016;34:e66. doi:10.1097/01.hjh.0000500023.92120.27

13. Imai Y, Kario K, Shimada K, et al. The Japanese Society of Hypertension guidelines for self-monitoring of blood pressure at home. Hypertens Res. 2012;35:777-795. doi:10.1038/hr.2012.56

14. James PA, Oparil S, Carter BL, et al. 2014 evidence-based guideline for the management of high blood pressure in adults: report from the panel members appointed to the Eighth Joint National Committee (JNC 8). JAMA. 2014;311:507-520. doi:10.1001/jama.2013.284427

15. Parati G, Stergiou GS, Asmar R, et al. European Society of Hypertension Practice guidelines for home blood pressure monitoring. J Hum Hypertens. 2010;24:779-785. doi:10.1038/jhh.2010.54

16. Hypertension WG, League $\mathrm{CH}$, Cardiology CS, Committee CMDAH, Care HB, Association HB. 2018 Chinese guidelines for the management of hypertension. Chin J Cardiol. 2019;24:24-56.

17. Baral-Grant S, Haque MS, Nouwen A, Greenfield SM, McManus RJ. Selfmonitoring of blood pressure in hypertension: a UK primary care survey. Int J Hypertens. 2012;2012:582068. doi:10.1155/2012/582068

18. Ostchega Y, Berman L, Hughes JP, Chen TC, Chiappa MM. Home blood pressure monitoring and hypertension status among US adults: the national health and nutrition examination survey (NHANES), 2009-2010. Am J Hypertens. 2013;26:1086-1092. doi:10.1093/ajh/hpt054

19. Ostchega Y, Zhang G, Kit BK, Nwankwo T. Factors associated with home blood pressure monitoring among US adults: national health and nutrition examination survey, 2011-2014. Am J Hypertens. 2017;30:1126-1132. doi:10.1093/ajh/hpx101
20. Liu J, Sun NL, Tang XH, Feng YQ. Investigation on the awareness and behavior model of home blood pressure monitoring in urban hypertensive subjects. Chin J Hypertens. 2016;24:423-427.

21. Hu DY, Liu LS, Yu JM, Yao CH. National survey of blood pressure control rate in Chinese hypertensive outpatients-China STATUS. Zhonghua Xin Xue Guan Bing Za Zhi. 2010;38:230-238.

22. Milot JP, Birnbaum L, Larochelle P, et al. Unreliability of home blood pressure measurement and the effect of a patient-oriented intervention. Can $J$ Cardiol. 2015;31:658-663. doi:10.1016/j. cjca.2015.03.006

23. Committee WC, Association CMD. Home blood pressure monitoring: a consensus document of China. Chin J Clin. 2012;40:69-72.

24. Shi J, Mo X, Sun Z. Content validity index in scale development. Zhong Nan Da Xue Xue Bao Yi Xue Ban. 2012;37:152-155. doi:10.3969/j.issn.1672-7347.2012.02.007

25. Lorig KR, Sobel DS, Ritter PL, Laurent D, Hobbs M. Effect of a self-management program on patients with chronic disease. Effect Clin Pract. 2001;4:256-262.

26. Hao YT, Sun XF, Fang JQ. The study of statistical methods used for item selection. Chin J Health Stat. 2004;21:209-211.

27. Wu ML. Questionnaire Statistical Analysis Practice: SPSS operation and Application. Chongqing: Chongqing university press; 2010.

28. He QY, Wang J, Zhang YL, Wang SH, Yang G. Item screening technique on clinical outcome rating scale which based on patient-reported outcomes. China J Tradit Chin Med Pharm. 2011;26:112-114.

29. DeVellis RF. Scale Development: Theory and Applications. London: Sage; 1991.

30. Wu ML. Structural Equation Model: Operation and Application of AMOS. Chongqing: Chongqing university press; 2010.

31. Curtin RB, Walters BA, Schatell D, Pennell P, Wise M, Klicko K. Self-efficacy and self-management behaviors in patients with chronic kidney disease. Adv Chronic Kidney Dis. 2008;15:191-205. doi:10.1053/j.ackd.2008.01.006
Patient Preference and Adherence

\section{Publish your work in this journal}

Patient Preference and Adherence is an international, peer-reviewed, open access journal that focusing on the growing importance of patient preference and adherence throughout the therapeutic continuum. Patient satisfaction, acceptability, quality of life, compliance, persistence and their role in developing new therapeutic modalities and compounds to optimize clinical outcomes for existing disease states are major areas of interest for the journal. This journal has been accepted for indexing on PubMed Central. The manuscript management system is completely online and includes a very quick and fair peer-review system, which is all easy to use. Visit http:/ www.dovepress.com/testimonials.php to read real quotes from published authors. 